\section{Estudo \\ CoDebate}

em Testão

Planejamento
Revista Estudo \& Debate, Lajeado, v. 24, n. 1, 2017. ISSN 1983-036X

DOI: http://dx.doi.org/10.22410/issn.1983-036X.v24i1a2017.1163

\title{
A DINÂMICA DA PRODUÇÁO E REPRODUÇÁO SOCIAL DOS PRODUTORES DE MAMONA VINCULADOS AO PROGRAMA NACIONAL DE PRODUÇÃO E USO DE BIODIESEL
}

\author{
Maria das Dôres Saraiva de Loreto ${ }^{1}$, Haudrey Germiniani Calvelli², Érika Cristine Silva ${ }^{3}$
}

\begin{abstract}
Resumo: $\mathrm{O}$ presente trabalho examina a dinâmica da produçáo e reproduçáo social dos arranjos produtivos de mamona, na Regiấo Nordeste do Brasil. A pesquisa fez uso do método survey, entrevistando 50 agricultores, vinculados ao Programa Nacional de Produção e Uso de Biodiesel (2012-2015). Resultados mostraram que, apesar de o programa ter potencializado maior adensamento societário, por meio do Selo Combustível Social e do Projeto de Polos de Produçáo de Biodiesel, os agricultores familiares da Região Nordeste têm enfrentado problemas para transformar a produçáo de mamona, em grande parte extrativa, em um cultivo organizado, por estarem inseridos em uma agricultura de subsistência, com pouco conhecimento técnico e gerencial. Concluise que a produçáo do biodiesel pela agricultura familiar somente poderia fomentar a formaçáo de arranjos produtivos locais sustentáveis, caso as açóes do PNPB estivessem atreladas a outras políticas sociais, tecnológicas e ambientais.
\end{abstract}

Palavras-chave: Arranjos produtivos agroenergéticos. Produção. Reprodução Social.

\section{DYNAMICS OF PRODUCTION AND SOCIAL REPRODUCTION OF PRODUCING CASTOR BEANS LINKED TO NATIONAL PRODUCTION PROGRAM AND BIODIESEL (2012-2015)}

\begin{abstract}
This paper examines the dynamic of production and social reproduction of productive arrangements of castor beans, in the region Northeast of Brazil. The research used the survey method, interviewing 50 farmers, linked to National Program for Production and Use of Biodiesel, Results showed that despite the program have potentiated greater corporate consolidation, through Social Fuel Seal and Project Poles of Biodiesel Production, family farmers in the Northeast Region have faced problems to transform the production of castor, in largely extractive, in an organized cultivation, by being inserted in subsistence agriculture, with little technical and managerial knowledge. It is concluded that biodiesel production by family farmers could only foment the
\end{abstract}

1 Professora do Programa de Pós-Graduação em Economia Doméstica-PPGED. Universidade Federal de Viçosa- Minas Gerais.

2 Cientista Social e doutora em Ciências Humans e Pós-doutoranda da UFV.

3 Mestranda do Programa de Pós-Graduação em Economia Doméstica-PPGED. Universidade Federal de Viçosa- Minas Gerais. 
formation of sustainable local production arrangements, if the actions of PNPB were linked to other social, technological and environmental policies.

Keywords: Agroenergetic Productive Arrangements. Production. Social Reproduction.

\section{INTRODUÇÃO}

A pobreza e as desigualdades sociais no espaço rural dificultam a capacidade de reprodução social das famílias, além de incentivar o êxodo rural. Segundo dados do Instituto Brasileiro de Geografia e Estatística (IBGE, 2010), entre os anos de 2000 e 2010, o êxodo rural atingiu mais de 835 mil jovens de 15 a 24 anos em todo o país. Por outro lado, a situação de pobreza do meio rural funciona, como ressalva Barbier (2000), como um obstáculo à conservação dos recursos naturais, dado que a população, encontrando-se despreparada para lidar com tais mudanças, de forma sustentável, acaba degradando o meio ambiente imediato.

O reconhecimento desses problemas tem exigido a promoção de novas estratégias para o desenvolvimento rural, que contemplem tanto a sustentabilidade social quanto econômica e ambiental, por meio de políticas públicas e práticas em atividades de desenvolvimento "de dentro para fora", que considerem as necessidades dos diversos setores e atores sociais, valorizando seus conhecimentos e experiências, suas potencialidades e matriz cultural. Conforme Araújo (2014) e Alves e Vasconcellos (2005), nesse tipo de desenvolvimento, também conhecido como endógeno, pressupōe-se a utilização, execução e valorização dos recursos humanos e materiais locais, de forma a elevar as oportunidades sociais e as condiçóes de vida da população, com contínua ampliação da capacidade de geração e agregação de valor sobre a produção, por meio de novos processos de aprendizagem, ampliação das redes produtivas e institucionais, assimilaçáo da inovaçáo tecnológica ou organizacional, garantindo a criação de riqueza e melhoria do bem-estar.

Essa exigência tem demandado do governo federal maiores iniciativas de desenvolvimento territorial, em termos de arranjos produtivos locais, que fomentem a autonomia e a identidade territorial e proporcionem condiçóes para a inclusão da agricultura familiar, como é o caso do Programa Nacional de Produçáo e Uso de Biodiesel (PNPB), cujas diretrizes se destacam pela implantação de açóes que elevem a qualidade de vida dos agricultores familiares; garantam preços competitivos, qualidade e suprimento, além da produção da bioenergia, a partir de diferentes fontes oleaginosas e em regióes diversas (VASCONCELLOS, 2016).

Assim, a produção e o uso de biocombustíveis tem sido uma das principais alternativas da matriz energética para atenuar o processo de degradaçáo da natureza e promover a inclusão da agricultura familiar. Pressupóe-se que essa alternativa traga mudanças significativas na vida dos produtores familiares do país, uma vez que o PNPB, criado em 2004 e regulamentado em 2005, mediante lei número 11097, tem como princípio norteador a segurança e soberania alimentar; a sustentabilidade dos sistemas de produção; a redução da pobreza rural e desenvolvimento territorial, por meio da inclusão de pessoas em regiốes, que estâo à margem do processo de desenvolvimento econômico, como é o caso da 
região nordeste do país e dos assentamentos de reforma agrária da região semiárida (Pessoa et al., 2007).

Segundo Favareto et al. (2008), a inclusão social do PNPB pode ocorrer através da combinação de diversos fatores, que podem interferir na inserção dos agricultores familiares na cadeia do biodiesel, sendo basicamente: (a) a política de aquisiçôes por intermédio de leilóes promovidos pela Agência Nacional de Petróleo, Gás Natural e Combustível (ANP); (b) a Concessão do Selo Combustível Social a empresas produtoras de biodiesel, a partir da compra dos grãos de oleaginosas da agricultura familiar (15\% para o Norte e Centro-Oeste e 30\% para o Sul, Sudeste e Nordeste) e das metas produtivas estabelecidas para as empresas vencedoras dos leilóes da ANP; (c) a política tributária, com a desoneração total e/ou parcial dos tributos federais para as empresas de biodiesel que adquirirem matérias-primas dos agricultores familiares; (d) a política de financiamento por intermédio de bancos públicos, e (e) e a política de suporte à organização da produção familiar, em termos do apoio à capacitação e à pesquisa, estímulo ao cooperativismo e implementação pelo Ministério do Desenvolvimento Agrário (MDA) do "Projeto Polos de Produção de Biodiesel".

Entretanto, para autores, como Loreto et al. (2012) e Penido (2011), o processo de inclusão social do PNPB tem apresentado controvérsias, uma vez que o programa tem sido sustentado pelo agronegócio da soja, o que tem dificultado a inclusão da agricultura familiar na produção do biodiesel. Assim, foi estruturada a presente pesquisa, que buscou responder aos seguintes questionamentos: Qual é o perfil dos agricultores que aderiram aos programas de produção e uso de biodiesel? Quais são as características dos sistemas de produção? Os programas têm contribuído para a reprodução social das famílias, isto é, para uma melhoria da qualidade de vida?

Pressupóe-se que as respostas às essas questóes, que contextualizam a temática a ser pesquisada, podem contribuir para evidenciar a forma como as famílias vivenciam as suas realidades cotidianas e qual seria diferencial da agricultura agroenergética sobre o processo de produção e reprodução das unidades familiares.

Nesse contexto, o trabalho objetivou analisar a dinâmica da produção e reprodução social dos produtores de mamona, vinculados ao PNPB da Região Nordeste do Brasil, considerando seu perfil pessoal e familiar, aspectos da produção e práticas tecnológicas, além das dimensóes da reprodução social, retratada pela qualidade de vida.

\section{REVISÃO DE LITERATURA: PRODUÇÃO E REPRODUÇÃO SOCIAL}

As concepçóes inerentes à de produção/reprodução social da teoria marxista pressupóem que o ser humano desenvolve meios para a satisfação de necessidades; ou seja, através do trabalho o ser humano interage com a natureza, retirando dela os meios para sua sobrevivência e, ao mesmo tempo, constrói-se como ser social estabelecendo relações sociais na esfera da produção/reprodução social (MARX, 1982).

Assim para agir sobre a natureza, os homens fazem uso das forças produtivas,

que "incluem, não apenas a dimensão imediatamente técnica, os elementos materiais da produção (ferramentas, fábricas, etc.), mas também a divisão social do trabalho e os elementos de ideologia, politica, direito, costumes etc." (ABESS, 1999, p. 10). Em suma, 
como acrescenta o autor, todo ato de trabalho não se limita à sua finalidade imediata, já que possibilita o desenvolvimento das capacidades humanas, das forças produtivas e das relaçôes sociais, tornando a sociedade mais desenvolvida e complexa, dando origem a relaçôes entre os homens, que não mais se limitam ao trabalho enquanto tal, que é denominado de reprodução social. São complexos sociais que surgem para atender às novas necessidades e possibilidades, postas pelo trabalho, para o desenvolvimento dos homens.

Nesse foco, Pfeifer e Adams (2016) identificam duas questóes: a) a produção dos meios para a sobrevivência humana, que significa a produção/reprodução da vida material, numa dimensão referente às condiçóes econômicas de produção; b) a produção/reproduçáo das relaçôes sociais de indivíduos, grupos e classes, numa dimensão da vida social que engloba a reprodução espiritual (formas de consciência social, jurídicas, filosóficas, artísticas, religiosas).

Nesse sentido, como afirmam Marx e Engels (1987), na reprodução dos modos de vida é importante não somente os processos materiais, mas também a sua dimensão imaterial - a cultura, os valores e ideologias, as sociabilidades em geral, a política, destacando:

\begin{abstract}
O modo pelo qual os homens produzem seus meios de vida depende, antes de tudo, da natureza dos meios de vida já encontrados e que têm de reproduzir. Não se deve considerar tal modo de produção de um único ponto de vista, a saber: a reprodução da existência física dos indivíduos. Trata-se, muito mais, de uma determinada forma de atividade dos indivíduos, determinada forma de manifestar sua vida, determinado modo de vida dos mesmos. Tal como os indivíduos manifestam sua vida, assim são eles. $\mathrm{O}$ que eles são coincide, portanto, com sua produçáo, tanto com o que produzem, como com o modo como produzem. O que os indivíduos são, portanto, depende das condiçôes materiais de sua produção (MARX; ENGELS, 1987, p. 27-28).
\end{abstract}

Os processos de produção e reprodução social vão depender, portanto, dos espaços de vivência, condiçôes de produção, trabalho e demais estruturas e práticas sociais. Exemplificando, as práticas de reprodução social das famílias inseridas na agricultura familiar podem, em geral, ser reconhecidas como:

\footnotetext{
Esse caráter familiar se expressa nas práticas sociais que implicam uma associação entre patrimônio, trabalho e consumo, no interior da família, e que orientam uma lógica de funcionamento específica. Não se trata apenas de identificar as formas de obtenção do consumo, por meio do próprio trabalho, mas do reconhecimento da centralidade da unidade de produção para a reprodução da família, através das formas de colaboração dos seus membros no trabalho coletivo - dentro e fora do estabelecimento familiar (WANDERLEY, 2009, p. 187).
}

Assim, situando o tema reprodução social no contexto da agricultura familiar, Pietrafesa (2000) entende que a busca da "reprodução social" está vinculada à elevaçáo da renda familiar, à inserção ao mercado e ao acesso a tecnologias, como também está associada, sobretudo, por "desejos" de "melhorar a vida", fixar os jovens (filhos) no meio rural, ampliar os ganhos em "qualidade de vida" (QV). 
Ou seja, essas duas dimensôes - reproduçáo social e qualidade de vida - estão intrinsecamente ligadas, uma vez que, do ponto de vista social e econômico, a reprodução do setor de agricultura familiar está, em certa medida, vinculada a sua capacidade de responder às demandas atuais de mercado, produtividade e elevação de renda, por um lado. Mas, por outro lado, quando as famílias assumem essa postura, fazem o discurso de que estão buscando por uma melhor "qualidade de vida".

Nesse sentido, o presente estudo usou como Proxy de reprodução social a categoria qualidade de vida, cujo principal referencial teórico se pauta na "motivação humana" ou na teoria sobre as "necessidades humanas", que possui duas vertentes: a econômica e a social.

Com relação à vertente econômica, a teoria tem suas raízes na literatura econômica keynesiana (KEYNES, 1972), que coloca as percepçôes das necessidades humanas no centro do progresso econômico, agrupando-as em duas classes: absolutas e relativas. Por outro lado, na vertente sociológica, a percepção das necessidades humanas é reforçada por Maslow (1970), quem sistematizou e hierarquizou os resultados das pesquisas empíricas acerca das necessidades humanas, concluindo que elas podem ser agrupadas em cinco grupos - fisiológico, segurança, emocional, psicológica e de autorrealizaçáo. Essa hierarquia de Maslow foi resumida por Alderfer (1969) em três categorias de necessidades humanas: necessidades de existência (materiais ou fisiológicas), de relacionamento humano significativo e necessidades de crescimento consigo mesmo e com o meio ambiente.

No presente estudo foi feito uso do modelo clássico de Metzen et al. (1980), que também se pautam na satisfação das necessidades humanas, que esses autores denominaram de domínios da vida, que são: segurança financeira (renda), trabalho, saúde, habitação, educação, família/parentes, vizinho-amigos, alimentação, lazer, ambiente, serviços comunitários, integração e segurança pessoal (FIGURA 1). 
Figura 1 - Modelo conceitual de qualidade de vida

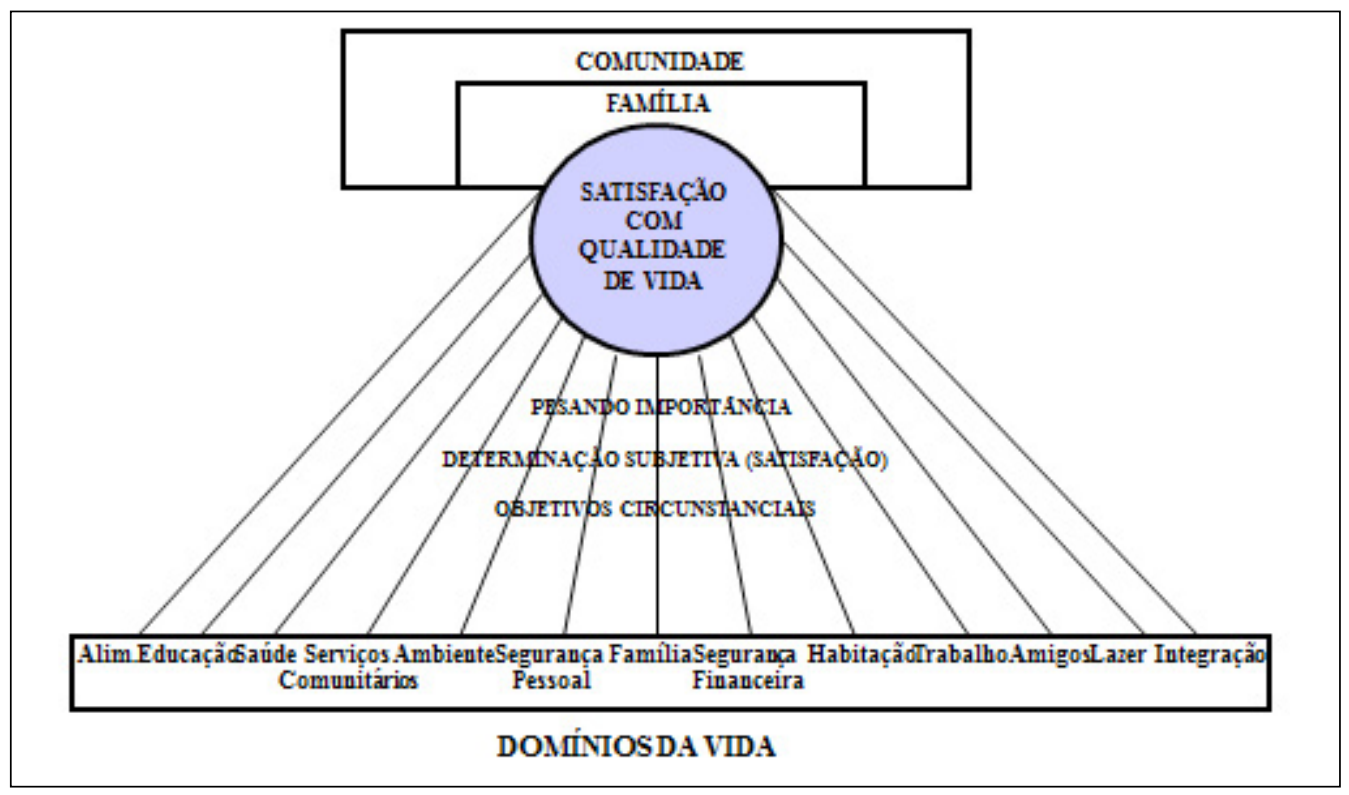

Fonte: Metzen et al. (1980), com adaptaçôes.

O diferencial desse modelo é que o mesmo considera tanto os aspectos subjetivos (satisfação e importância) quanto as condiçôes dos elementos específicos ou concretos do ambiente, que inclui pessoas e infraestruturas e que devem estar no bojo das experiências de vida das famílias. O modelo baseia-se na premissa de que a satisfação com a qualidade de vida dos agricultores e suas famílias, dentro de um contexto ou ambiente (comunidade, grupos de convivência), está em função da satisfação com vários domínios ou componentes da vida e, ao mesmo tempo, da importância dos mesmos no ciclo vital para os objetivos e metas, de curto, médio e longo prazo. Nesse sentido, a qualidade de vida deve abranger domínios ou componentes concretos da vida dos indivíduos e famílias, como também as suas percepçóes e avaliaçóes subjetivas.

\section{METODOLOGIA}

O trabalho de natureza quanti-qualitativa foi do tipo descritivo-exploratório, tendo como unidade empírica de análise os agricultores e agricultoras da Região Nordeste. Como estratégia de pesquisa, adotou-se o método do estudo de caso, aqui entendido como uma forma particular de investigação do real, onde são coletados e registrados dados, para uma posterior interpretação, tendo como objetivo a reconstrução, em bases científicas, dos fenômenos observados.

Por ser uma estratégia de pesquisa, Yin (2005) considera que o estudo de caso pode contribuir para o conhecimento de aspectos individuais, organizacionais, sociais, políticos, de grupos e outros relacionados, quando o investigador tem pouco controle sobre os 
eventos e quando o foco é sobre um fenômeno contemporâneo dentro do contexto da vida cotidiana.

A população estudada compreendeu os agricultores familiares da Região Semiárida do Ceará (CE), no Nordeste do Brasil, especificamente aqueles que aderiram à produção agroenergética, com o plantio de mamona, tendo como incentivo a Petrobrás Biocombustível, como principal agente financiador e impulsionador da produção agroenergética na Região Nordeste.

Considerando o universo populacional foi delimitada uma amostra aleatória e estatisticamente significante de 50 produtores nordestinos, espacialmente distribuídos no município de Monsenhor Tabosa/CE, especificamente nas seguintes comunidades: Terra Teima, Cachoeirinha, Bargado, Curitiba, Santana, Vista Alegre/Taboa e Agrobel.

Para a obtenção de uma visão global da realidade foram utilizados diferentes métodos de coleta de dados, provenientes de fontes secundárias e primárias. Além disso, procurouse combinar métodos de natureza qualitativa e quantitativa. Como ressalta Goldemberg (2001), a interação da pesquisa quantitativa e qualitativa permite que o pesquisador faça um cruzamento de seus dados, teorias e conclusóes com maior confiabilidade, não se limitando a uma única técnica, podendo recorrer a outros procedimentos, investigando as questóes em diferentes ocasióes e recorrendo às fontes documentais e dados estatísticos, num intenso e permanente diálogo.

Assim, os métodos para o levantamento das informaçóes foram: a) Revisão bibliográfica sobre dados históricos locais, através de registros censitários e documentais da produção agroenergética, visando examinar a realidade dessa produção; b) Para a coleta de dados junto aos agricultores (as) foi aplicado o método Survey, mediante o uso de questionários, que permitiram identificar o perfil pessoal e familiar dos produtores, em termos de sexo, idade, estado civil, naturalidade, grau de instrução e nível de escolaridade e condiçóes de trabalho, tipo de família, número de filhos, ciclo de vida; caracterizar os sistemas de produção, por meio do histórico do uso da terra e práticas agrícolas adotadas, desde o plantio até a comercialização; e examinar a satisfação dos agricultores com diferentes componentes ou domínios da qualidade de vida. Para tanto, foi feito uso de uma escala que variou de 1 a 4, categorizando o nível de satisfação (muito insatisfeito, insatisfeito, satisfeito, muito satisfeito) com os domínios da vida, em função da opiniâo e avaliação que o público entrevistado possuía de suas próprias condições de vida, antes e após a introdução do cultivo agroenergético.

O tratamento analítico dos dados quantitativos foi feito pelas técnicas da estatística descritiva (média, frequência e análise tabular); enquanto que os dados qualitativos foram examinados por meio da análise temática, conforme metodologia proposta por Bardin (2011).

\section{RESULTADOS E DISCUSSÃO}

No intuito de obter maior conhecimento sobre a realidade dos produtores inseridos no PNPB, buscou-se caracterizar seu perfil pessoal e familiar, características do processo 
de produção e dimensão tecnológica, contribuição do PNPB na qualidade de vida dos agricultores e suas respectivas famílias.

\subsection{Perfil pessoal e familiar dos agricultores inseridos no PNPB}

Em função dos dados apresentados no Quadro 1, constatou-se um predomínio de homens $(98,0 \%)$ comparativamente às mulheres $(2,0 \%)$, demonstrando a superioridade masculina, em termos de posse da terra, sendo a grande maioria casada $(96,0 \%)$. A idade média de idade dos entrevistados era de 46,5 anos, sendo a mínima de 26 anos e a máxima de 77 anos. Distribuindo-se os entrevistados por faixa etária, notou-se que mais da metade (58\%) encontrava-se na faixa etária de 41 a 60 anos; outros tinham de 20 a 40 anos (28\%); enquanto a faixa etária com menor número de pessoas foi a de mais de 60 anos (14\%).

Quadro 1- Perfil Pessoal dos Produtores, Ceará, Brasil

\begin{tabular}{|c|c|c|}
\hline Componentes & Unidade & Produtores do Ceará \\
\hline \multicolumn{3}{|l|}{ 1- Sexo Masculino } \\
\hline - Masculino & $\%$ & 98,0 \\
\hline - Feminino & $\%$ & 2,0 \\
\hline \multicolumn{3}{|l|}{ 2- Estado Civil } \\
\hline - Casado & $\%$ & 96,0 \\
\hline • Viúvo & $\%$ & 2,0 \\
\hline - Separado/Divorciado & $\%$ & 2,0 \\
\hline 3- Idade Média & No Anos & 46,5 \\
\hline \multicolumn{3}{|l|}{ 4- Condição legal da terra } \\
\hline - Proprietário & $\%$ & 68,0 \\
\hline - Ocupante & $\%$ & 8,0 \\
\hline - Outros & $\%$ & 18,0 \\
\hline - Não responderam & $\%$ & 6,0 \\
\hline \multicolumn{3}{|l|}{ 5- Tempo de posse da terra } \\
\hline - Inferior a 18 anos & $\%$ & 4,0 \\
\hline - Superior a 18 anos & $\%$ & 46,0 \\
\hline • Não responderam & $\%$ & 50,0 \\
\hline \multicolumn{3}{|l|}{6 - Residência no campo } \\
\hline - No campo & $\%$ & 100,0 \\
\hline - Cidade & $\%$ & - \\
\hline 7- No de vezes de ida à cidade & Média & 13,6 \\
\hline 8- Nível de Escolaridade & No Anos & 4,6 \\
\hline
\end{tabular}

Fonte: Dados da Pesquisa (2013). 
Com respeito ao local de moradia, constatou-se que a maioria dos entrevistados residia no meio rural, sendo naturais do próprio estado, preferencialmente dos municípios de Monsenhor Tabosa (54\%) e Tamboril (24\%), no Estado do Ceará. Em termos percentuais médios em torno de $68 \%$ dos entrevistados eram proprietários; sendo que a maioria tinha um tempo superior a 18 anos de posse da terra. Apesar dos produtores não terem feito quase nenhuma mudança, nos últimos 3,0 anos, e de todos residirem no campo (100,0\%), os mesmos náo se encontravam isolados no meio rural, já que, em termos percentuais médios, iam à cidade 13,6 vezes, no ano.

No que se refere à escolaridade, constatou-se que $26 \%$ dos agricultores entrevistados eram alfabetizados. Dentre aqueles que estudaram, a média foi de 4,6 anos de estudo; ou seja, possuíam o ensino fundamental incompleto. Os dados da Figura 2 mostram que quase a totalidade dos produtores estudou, existindo apenas $2 \%$ analfabetos, mas que foram poucos os produtores que conseguiram alcançar o curso superior.

Figura 2 - Percentual de Escolaridade dos agricultores, Ceará/Brasil

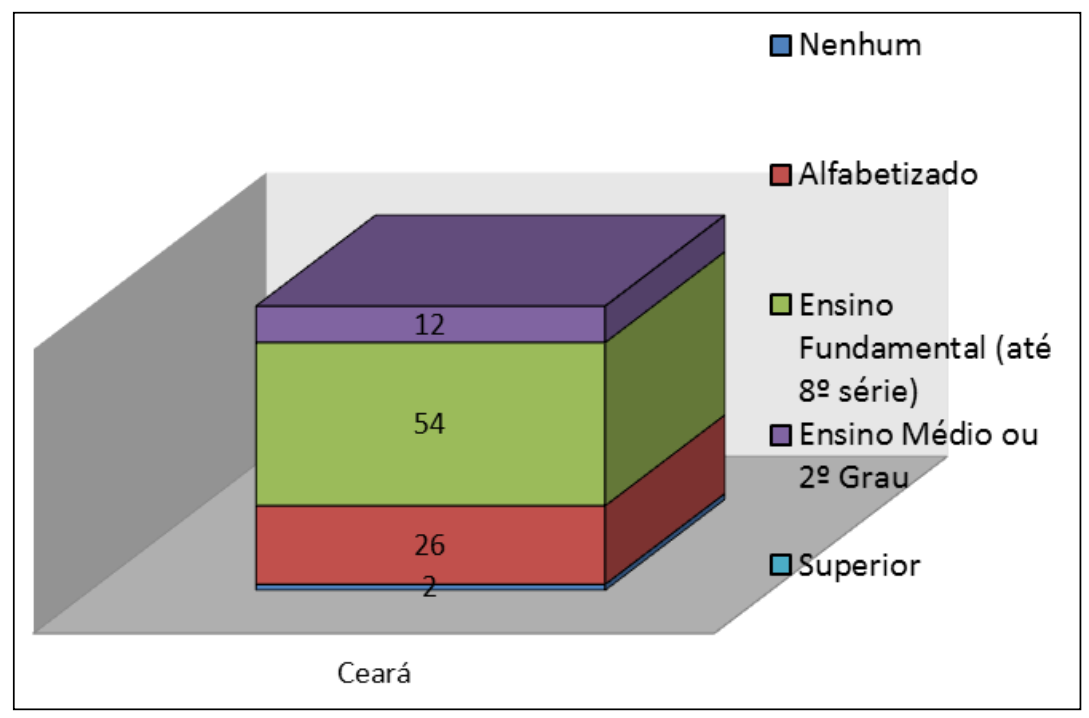

Fonte: Dados da Pesquisa (2013).

Os diversos aspectos do perfil familiar dos produtores entrevistados, relacionados no Quadro 02, revelam que $80 \%$ das famílias tinham de 3,0 a 6,0 membros, sendo o tamanho médio de 3,9 membros e o número médio de filhos equivalente a 1,9. Esses dados são semelhantes àqueles constatados no âmbito nacional (tamanho médio da família de 3,2 membros, com 1,86 filhos), conforme registrado pelo IBGE (2010).

As famílias entrevistadas possuíam um maior número de filhos na faixa etária acima de 18 anos (37,7\%), seguidos de 7 a 14 anos (32,6\%) e dos filhos adolescentes (24,5\%). Os filhos eram preferencialmente do sexo masculino, com idade acima de 18 anos $(39,1 \%)$, basicamente solteiros (93\%) e com escolaridade média que variou de 3 a 18 anos de estudo, 
sendo que $23,3 \%$ dos mesmos trabalhavam na propriedade, colaborando com pai e a mãe, nas atividades produtivas.

Quadro 2 - Aspectos do Perfil Familiar dos Produtores Entrevistados, Ceará/Brasil

\begin{tabular}{|c|c|c|}
\hline Aspectos & Unidade & Ceará \\
\hline \multicolumn{3}{|l|}{ 1. Número de Componentes } \\
\hline Até 2 & $\%$ & 16,0 \\
\hline 3 a 4 & $\%$ & 46,0 \\
\hline 5 a 6 & $\%$ & 34,0 \\
\hline 7 e mais & $\%$ & 4,0 \\
\hline 2. Tamanho Médio da Família & No & 3,9 \\
\hline 3. Número Médio de Filhos & No & 1,9 \\
\hline 4. Presença de Agregados & $\%$ & 2,0 \\
\hline \multicolumn{3}{|l|}{ 5.Tipo de Família } \\
\hline 5.1 Nuclear & & 92,0 \\
\hline 5.2 Monoparental & & 4,0 \\
\hline 5.3 Extensa & & 4,0 \\
\hline \multicolumn{3}{|l|}{ 6. Ciclo de Vida } \\
\hline 6.1 Formação & $\%$ & 20,0 \\
\hline 6.2 Maturação & $\%$ & 36,0 \\
\hline 6.3 Dispersão & $\%$ & 28,0 \\
\hline 6.4 Outras & $\%$ & 16,0 \\
\hline \multicolumn{3}{|l|}{ 7. Faixa Etária dos Filhos } \\
\hline 7.1 Menos de 1 ano de idade & $\%$ & 1,0 \\
\hline 7.2 De 2 a 3 anos de idade & $\%$ & 2,0 \\
\hline 7.3 De 4 a 6 anos de idade & $\%$ & 2,0 \\
\hline 7.4 De 7 a 14 anos de idade & $\%$ & 32,6 \\
\hline 7.5 De 15 a 17 anos & $\%$ & 24,5 \\
\hline 7.6 De 18 a 24 anos & $\%$ & 23,5 \\
\hline 7.7 De 25 e mais de idade & $\%$ & 14,2 \\
\hline \multicolumn{3}{|l|}{ 8. Idade do Chefe } \\
\hline 8.1 Até 34 anos & $\%$ & 10,0 \\
\hline 8.2. De 35 a 49 anos & $\%$ & 56,0 \\
\hline 8.3 De 50 anos a mais & $\%$ & 34,0 \\
\hline
\end{tabular}

Fonte: Dados da Pesquisa (2013). 
A distribuição das famílias segundo a composição do seu parentesco mostra, conforme a Figura 3, que, em termos médios, 92,0\% das famílias pesquisadas eram nucleares (formadas pelo casal e filhos), tal como tem sido constatado na maioria dos estudos demográficos. Segundo Klaas Woortmann e Ellen Woortmann (2004), os grupos domésticos brasileiros têm se tornado mais heterogêneo, apesar de que continue predominando a "família nuclear", inclusive sobre as unidades familiares monoparentais. De acordo com Azevedo (2012), há um predomínio do arranjo monoparental feminino, quando é chefiado por uma mulher que não tem cônjuge, que está presente em $35 \%$ dos domicílios brasileiros, com maior incidência na área urbana, embora esteja crescendo no meio rural, conforme dados da Pesquisa Nacional por Amostra de Domicílios (PNAD), realizada no ano de 2009.

Figura 3 - Distribuição dos Tipos de Famílias, Ceará/Brasil.

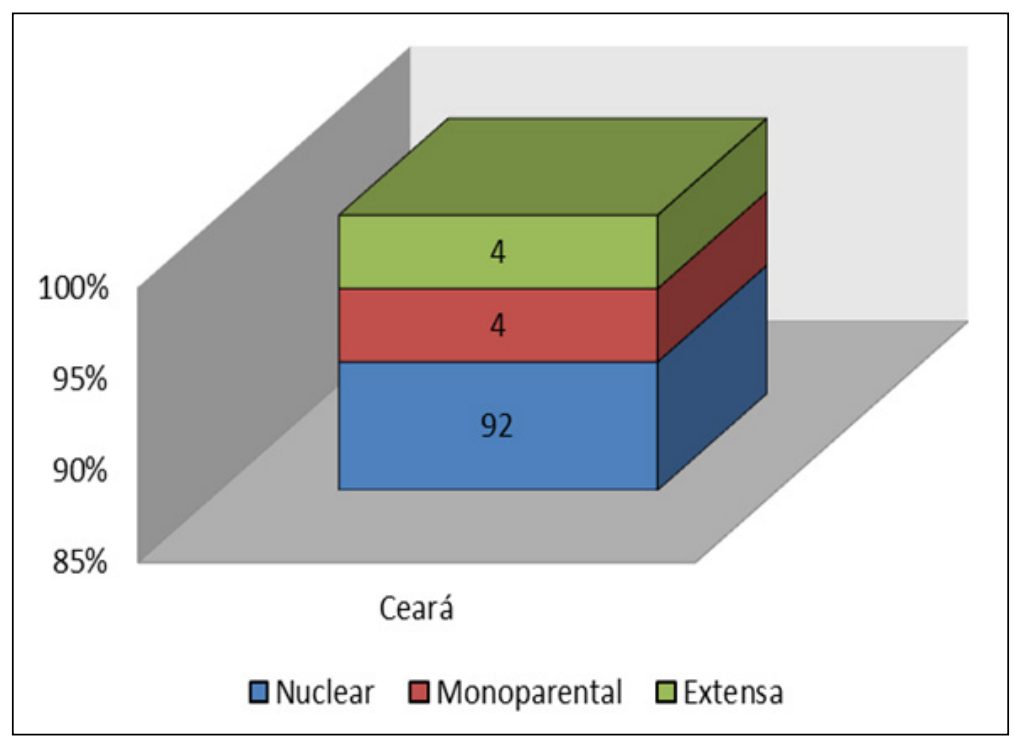

Fonte: Dados da Pesquisa (2013).

A tendência à nuclearização e do número médio de 1,9 filhos por família indica a maior presença da família formada pelo pai, mãe e dois filhos. Posteriormente, tem-se o caso das famílias extensas (4,0\%), que são aquelas formadas pelo casal e filhos, acrescidas de parentes e não parentes; sendo também insignificante o número de famílias quebradas ou monoparentais (com apenas um dos cônjuges), equivalente a $4,0 \%$ do total de unidades familiares pesquisadas. Assim, relativamente, poucas famílias contavam com outros parentes agregados adultos, predominantemente irmãos e sobrinhas, do sexo masculino e feminino, respectivamente. 
Com respeito à etapa do ciclo de vida ${ }^{4}$, as famílias pesquisadas encontravam-se principalmente na fase de maturação $(36,0 \%)$, seguidas daquelas em fase de dispersão $(28,0 \%)$. Nesta etapa sáo maiores as possibilidades de o casal dividir o encargo da manutenção da família com os filhos, já que os mesmos são adultos, com idade para se integrar ao trabalho.

Assim, os dados demonstraram que, em geral, o produtor compartilha suas responsabilidades com o cônjuge, filhos e outros parentes. Os filhos eram preferencialmente do sexo masculino, com idade acima de 18 anos (37,7\%), basicamente solteiros (93\%) e com escolaridade média que variou de 3 a 18 anos de estudo, sendo que 48,9\% desses mesmos trabalhavam na propriedade e colaboravam com pai e a mãe, nas atividades produtivas.

Quanto ao status ocupacional dos membros familiares, observou-se que o número médio de pessoas ocupadas nas famílias foi de 1,7 pessoas, com predomínio de 1 membro ocupado (42,0), seguido por 2 membros $(38,0 \%)$, que foram identificados como: Produtor, cônjuge e filhos maiores de 18 anos. Existe uma maior proporção de filhos ocupados com mais de 18 anos (66,7\%), comparativamente aos cônjuges (39,1\%). Com respeito aos agregados pode-se observar que, em torno de $25 \%$ dos mesmos, encontravam-se envolvidos com alguma atividade laboral.

\subsection{Sistema de Produção: Uso das Terras e Dimensão Técnica}

No contexto do sistema de produção, examinou-se o fator de produção "terra", em termos de suas condiçóes físicas e pelo histórico do seu uso, antes e depois do cultivo agroenergético, bem como a dimensão técnica dos sistemas de produção.

A terra em Ceará era formada pela Caatinga, sendo a textura do solo basicamente arenosa. As características do seu relevo mostram um predomínio de solos ondulados e os recursos hídricos disponíveis às unidades produtivas eram, na sua maioria, provenientes de rios e córregos.

Constatou-se o predomínio de pequenas propriedades, nas comunidades de Santana, Tira teima, Agrobel, Cachoeirinha, Bargado, Curitiba e Vista alegre, que praticamente não variou, quando foi introduzido o cultivo agroenergético, plantado geralmente em consórcio com cultivos temporários. As comunidades Santana e Tira Teima possuem áreas de cultivos e pastagens coletivas, sendo a área total de Santana de 3.213,0 hectares e de Tira Teima $1.033,0$ hectares. Nas duas comunidades são destinados 3,0 hectares para cada família para o cultivo temporário e permanente, sendo cultivado tanto milho quanto feijão consorciado com a mamona. As demais comunidades possuíam, em média, 2,5 hectares de cultivo temporário; 2,25 de cultivo permanente e de cultivo agroenergético.

4 Conforme Montali (1990), o ciclo de vida da família pode ser constituído de 3 etapas: Formaçáo, quando os pais são jovens, até 35 anos, podem não ter filhos ou que sejam crianças (menores de 12 anos); Maturação, se os pais possuem, geralmente, de 35 a 49 anos e têm, no núcleo familiar, filhos adolescentes ou acima de 12 anos; Dispersão, geralmente, os pais são mais velhos, ou seja, têm idade acima de 50 anos e todos seus filhos são adultos (acima de 21 anos), existindo alguns que não residem mais no domicílio. 
$\mathrm{Na}$ análise do perfil dos sistemas usuais de produçâo procurou-se identificar as tecnologias, utilizadas nas diferentes fases do processo produtivo: análise e preparo do solo, forma de plantio, rotaçấo, adubação, correção, tratos culturais, controle de pragas e doenças, irrigação, colheita, produção e armazenagem. O perfil usual médio de produção, apresentado no Quadro 3, permitiu constatar que:

a) Apenas $2 \%$ dos produtores faziam análise do solo;

b) Utilizavam tração mecânica, preferencialmente, no preparo do solo (80\%);

c) O plantio era de forma manual (78\%), tendo em média 3 homens trabalhando por hora; fazendo uso das sementes ganhadas pelo PNPB, todos utilizando espaçamento de $3 \times 1$;

d) A prática da rotação só foi realizada por $20 \%$ dos produtores, assim como não foi comum a presença de área de pousio;

e) A adubação química do solo não era empregada pelos agricultores de Ceará, somente a orgânica (82\%);

f) A correção do solo destinado ao cultivo de mamona não era feita por nenhum dos produtores;

g) A grande maioria dos produtores fazia o controle de ervas e plantas daninhas (94\%), utilizando como método a capina, em média, 2,5 vezes no período do cultivo;

h) O controle de pragas e de doenças não foi empregado pelos agricultores do Ceará;

i) A irrigação não esteve presente no sistema de produção nordestino;

j) O processo de colheita da cultura de mamona era realizado de forma manual em todas as propriedades;

k) A produção média do cultivo da mamona foi de $730,08 \mathrm{~kg}$, sendo que quase todos os agricultores comercializam o produto para a Petrobrás Biocombustível (PBio), cobrando um preço em média de 0,87 centavos o quilo.

Quadro 3 - Aspectos gerais dos Sistemas Usuais das lavouras para o cultivo de mamona, Ceará/Brasil

\begin{tabular}{|l|c|c|}
\hline \multirow{2}{*}{\multicolumn{1}{|c|}{ Práticas }} & \multicolumn{2}{|c|}{ Produtores Ceará } \\
\cline { 2 - 3 } & No & \% \\
\hline 1. Análise do Solo & 1 & 2,0 \\
\hline 2. Preparo do solo & 50 & 100,0 \\
\cline { 2 - 3 } 2.1. Preparo mecanizado & 40 & 80,0 \\
\cline { 2 - 3 } 2.3. Preparo manual & 10 & 20,0 \\
\hline 3. Plantio manual & 39 & 78,0 \\
\hline 4. Rotação & 10 & 20,0 \\
\hline
\end{tabular}




\begin{tabular}{|l|c|c|}
\hline \multirow{2}{*}{\multicolumn{1}{|c|}{ Práticas }} & \multicolumn{2}{|c|}{ Produtores Ceará } \\
\cline { 2 - 3 } & No & \% \\
\hline 5. Adubação & 41 & 82,0 \\
\cline { 2 - 3 } 5.1. Adubação Química & 0 & 0,0 \\
\cline { 2 - 3 } 5.2. Adubação Orgânica & 41 & 82,0 \\
\cline { 2 - 3 } 5.3. Química e Orgânica & 0 & 0,0 \\
\hline 6. Correção do solo & 0 & 0,0 \\
\hline 7. Tratos Culturais & 47 & 94,0 \\
\hline 8. Controle de Pragas & 0 & 0,0 \\
\hline 9. Controle de Doenças & 0 & 0,0 \\
\hline 10. Irrigação & 0 & 0,0 \\
\hline 10.1. Irrigação mecânica & 0 & 0,0 \\
\cline { 2 - 3 } 10.1. Irrigação manual & 0 & 0,0 \\
\hline 11. Colheita & 50 & 100,0 \\
\hline 12. Produção & 50 & 100,0 \\
\hline 13. Comercialização & 50 & 100,0 \\
\hline
\end{tabular}

Fonte: Dados da Pesquisa (2013).

\subsection{Contribuiçáo do PNPB na vida dos produtores}

Os produtores do Ceará associavam o plantio do cultivo agroenergético com outras atividades da propriedade, afirmando que a mamona plantada em consórcio com o milho, feijão ou outra cultura possibilitou o crescimento da produçáo agrícola e da renda familiar.

Assim, a introduçâo do Cultivo Agroenergético na propriedade foi devido à possibilidade de se obter uma renda maior na agricultura familiar (50\%). Além disso, 24\% dos entrevistados afirmaram que o incentivo do governo e apoio da Petrobrás no plantio e na comercialização da produção foram os motivos para o plantio da mamona; enquanto o restante acrescentou que o motivo foi derivado pelo fato de ter tido capacitaçáo, orientaçáo técnica e pela própria mobilização social.

A maioria dos agricultores não realizou mudanças no seu sistema de produção, tampouco foram feitos investimentos; comentando que o cultivo agroenergético foi uma atividade a mais para a família. Como discute Rovaris (2013), o cultivo da mamona, na Regiáo Nordeste, pode ser visto com uma atividade marginal e sua reduzida capacidade de geraçáo de renda deve-se à baixa produtividade e à fragilidade institucional dos agricultores, o que limita a implantação de bases organizadas para a viabilizaçấo dos arranjos produtivos locais.

Outro aspecto destacado pelos agricultores do Nordeste foi a aquisição de novos conhecimentos/informaçóes sobre a prática de cultivo da mamona e sobre o programa, por meio de reuniōes, capacitaçóes, orientaçōes e visitas técnicas. Além disso, foram geradas novas relaçóes e parcerias. As principais redes ativadas no Ceará foram: COOPTRACE, 
Petrobrás e MST, além dos técnicos da assistência técnica, na implantação do Cultivo Agroenergético.

As expectativas futuras quanto ao programa são incertas, considerando o problema da seca no estado do Ceará, apesar de que todos os produtores terem afirmado que iriam continuar plantando, se houvesse inverno, com possibilidades de aumento da área de plantio; dando, assim, continuidade ao programa, com reflexos sobre a qualidade de vida.

\subsection{Qualidade de Vida dos Sistemas Familiares}

Os resultados apontaram mudanças na qualidade de vida dos agricultores a partir de suas percepçóes sobre as transformaçôes ocorridas na sua vida cotidiana, com respeito aos diferentes componentes ou domínios da vida, propostos no modelo de Metzen et al. (1980).

Em termos do significado de qualidade de vida, a grande maioria dos entrevistados (76\%) associou esse termo com saúde e aumento da renda, não deixando de citar outros aspectos, tais como: ter uma boa alimentação, ter instrução e ter uma vida de melhor qualidade, além do fortalecimento do cultivo. De acordo com os dados, apresentados no Quadro 4, pode-se constatar que o nível médio de satisfação total dos produtores depois da introdução do cultivo agroenergético foi de 97,2\%, influenciado pelos componentes que demonstraram um índice de satisfação superior a 95\%, que foram: renda, trabalho, saúde, educação, relacionamento com a família/parentes e com amigos/vizinhos, segurança pessoal e ambiente onde vive.

Quadro 4 - Nível de Satisfação dos Produtores Rurais com os Diferentes Domínios da Vida, Sem e Com o Cultivo de Mamona, Ceará/Brasil

\begin{tabular}{|l|c|c|c|c|c|c|c|c|}
\hline \multirow{2}{*}{ Domínios da Vida } & \multicolumn{2}{|c|}{$\begin{array}{c}\text { Extremamente } \\
\text { Insatisfeito }\end{array}$} & \multicolumn{2}{c|}{$\begin{array}{c}\text { Insatisfeito } \\
\%\end{array}$} & \multicolumn{2}{c|}{$\begin{array}{c}\text { Satisfeito } \\
\%\end{array}$} & \multicolumn{2}{c|}{$\begin{array}{c}\text { Extremamente } \\
\text { Satisfeito } \\
\%\end{array}$} \\
\cline { 2 - 10 } & Sem & Com & Sem & Com & Sem & Com & Sem & Com \\
\hline Renda & 2,0 & - & 89,0 & - & 9,0 & 96,0 & - & 4,0 \\
\hline Trabalho & - & - & 77,0 & 2,0 & 23,0 & 98,0 & - & - \\
\hline Saúde & - & - & 45,0 & - & 55,0 & 100,0 & - & - \\
\hline Moradia & - & - & 33,0 & - & 67,0 & 91,0 & - & 9,0 \\
\hline Educação & - & - & 29,0 & - & 71,0 & 98,0 & - & 2,0 \\
\hline FamílialParentes & - & - & 29,0 & - & 71,0 & 100,0 & - & - \\
\hline Vizinhos\Amigos & - & - & 26,0 & - & 74,0 & 100,0 & - & - \\
\hline Alimentação & - & - & 55,0 & 2,0 & 45,0 & 92,0 & - & 6,0 \\
\hline Lazer & - & - & 31,0 & 6,0 & 69,0 & 94,0 & - & - \\
\hline Ambiente & - & - & 37,0 & - & 63,0 & 100,0 & - & - \\
\hline Serviços Comunitários & - & - & 46,0 & - & 54,0 & 100,0 & - & - \\
\hline
\end{tabular}




\begin{tabular}{|l|c|c|c|c|c|c|c|c|}
\hline \multirow{2}{*}{ Domínios da Vida } & \multicolumn{2}{|c|}{$\begin{array}{c}\text { Extremamente } \\
\text { Insatisfeito } \\
\end{array}$} & \multicolumn{2}{|c|}{$\begin{array}{c}\text { Insatisfeito } \\
\%\end{array}$} & \multicolumn{2}{c|}{$\begin{array}{c}\text { Satisfeito } \\
\%\end{array}$} & \multicolumn{2}{c|}{$\begin{array}{c}\text { Extremamente } \\
\text { Satisfeito } \\
\%\end{array}$} \\
\cline { 2 - 10 } & Sem & Com & Sem & Com & Sem & Com & Sem & Com \\
\hline Vida Espiritual & - & - & 20,0 & - & 80,0 & 95,0 & - & 5,0 \\
\hline Segurança Pessoal & - & - & 24,0 & - & 76,0 & 100,0 & - & - \\
\hline Média & $\mathbf{0 , 2}$ & - & $\mathbf{4 1 , 6}$ & $\mathbf{0 , 8}$ & $\mathbf{5 8 , 2}$ & $\mathbf{9 7 , 2}$ & - & $\mathbf{2 , 0}$ \\
\hline
\end{tabular}

Fonte: Dados de Pesquisa (2013).

Por outro lado, o nível médio de insatisfação, por parte dos produtores, com a introdução do cultivo agroenergético foi de apenas $0,8 \%$, com destaque para o lazer, seguido do trabalho e alimentação, bem aquém dos $41,6 \%$, que se encontravam anteriormente insatisfeitos. A precariedade dos serviços públicos indica a necessidade de que o setor público direcione recursos para infraestruturas comunitárias; bem como para criar oportunidades de geração de trabalho e renda.

Os resultados demonstraram que o PNPB colaborou para o aumento da renda das famílias pesquisadas, no Ceará, visto que, através do incentivo e da assistência técnica, muitos agricultores conseguiram ter alternativas de produção. Apesar do valor obtido com a venda da mamona não ter acarretado mudanças significativas no padrão de vida familiar gerou possibilidades de no futuro, com o aumento do plantio, obter uma renda maior. A percepção dos agricultores quanto à melhoria da qualidade de vida está associada ao fato de que o aumento da renda possibilitou a aquisição de roupas, eletrodomésticos, móveis, motos e, ainda, a ampliação da casa.

Entretanto, considera-se que esses bens de consumo, apesar de agregar maior satisfação, não produzem mudanças estruturais na vida dos membros familiares, isto é, não são capazes de prover o empoderamento dos agricultores, em termos de controle dos próprios assuntos, produção, criação e geração de novas alternativas, mobilização de energias para o respeito a seus direitos, mudança das relaçóes de poder e obtenção do controle sobre os recursos (físicos, humanos e financeiros) e, também, sobre a ideologia (crenças, valores, atitudes), para poder discernir como escolher e levar a cabo as próprias opçóes (VILLACORTA; RODRIGUEZ, 2002). Ou seja, todos os membros da família continuam a exercer o mesmo papel na comunidade onde moram, não possuem acesso integral à saúde; continuam dependentes dos benefícios sociais do governo, como a bolsa-família, perca, com limitada participação e autonomia.

Mas, conforme a Figura 4, na percepção dos agricultores, de um modo geral, o nível médio de satisfação total passou de $58,2 \%$ para $97,2 \%$, indicando que quase a totalidade dos agricultores sentia-se satisfeita com a sua qualidade de vida; ocorrendo, inclusive, que, dos 13 domínios da vida, todos apresentaram uma situação de melhoria. 
Figura 4 - Índice de Satisfação Total dos Produtores em relação à Qualidade de Vida, Sem e Com o Cultivo Agroenergético, Ceará/Brasil

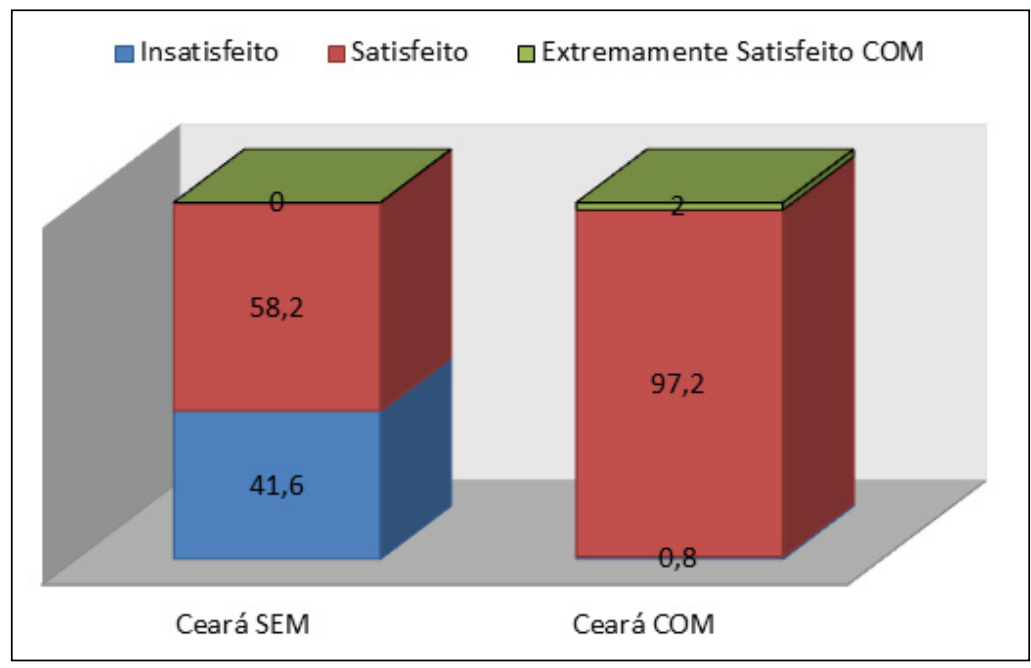

Fonte: Dados da Pesquisa (2013).

Considerando a teoria das necessidades humanas, desenvolvida por Maslow (1970), pode-se inferir que os produtores entrevistados têm nas necessidades relativas sua valorização máxima, muito embora as necessidades materiais (de segurança e de sobrevivência) sejam significativas para sua qualidade de vida. Isto pode ser verificado pela importância atribuída à família, amigos e educação, fatores que estão diretamente relacionados tanto com as necessidades de relacionamento humano com pessoas significativas, quanto com as necessidades de crescimento e autorealização.

Como diz Engberg (1992), a qualidade de vida das pessoas, como indivíduos ou grupos, não depende somente das necessidades materiais ou de existência, mas é também influenciada pela capacidade da família em se adaptar e se relacionar com pessoas significantes e com as instituiçóes de forma a desenvolver-se como um sistema sustentável.

\section{CONCLUSÃO}

Apesar do discurso do PNPB de conjugar eficiência produtiva com equidade social por meio da inclusão da agricultura familiar na cadeia produtiva do biodiesel, o programa não atentou para as especificidades locais, em termos de recursos físicos, financeiros e socioculturais, pautando-se basicamente em uma lógica produtivista e econômica, estando os cultivos agroenergéticos da Região Nordeste, como atividades secundárias e marginais. Os impasses entre a agricultura familiar e o setor produtivo são constantes, pelo fato dos agricultores serem periféricos, em termos da limitada capitalização, capacitação e cultura organizacional.

Assim a pressão dos produtores de biodiesel e a correlação de forças econômicas e políticas envolvidas no $\mathrm{PNPB}$, dentro e fora do governo, somadas às preocupaçóes quanto 
à efetividade do programa, induziram a adoção de uma estratégia que priorizou a garantia da oferta do biocombustível.

Mesmo diante dos impasses existentes, as famílias nordestinas, basicamente nucleares, consideram que houve uma melhoria da qualidade de vida, influenciada pelo aumento da renda, que possibilitou o consumo de bens desejados. Entretanto, considera-se que o acesso a uma renda instável, dependente das condiçóes climáticas, não conduz a um processo de construçáo e, ou, ampliação das capacidades, bem como de controle sobre os recursos.

Assim, o cenário de pobreza e de desigualdades sociais no espaço rural nordestino tem dificultado a capacidade de reprodução social dos agricultores familiares, uma vez que as famílias continuam dependentes dos benefícios e transferências governamentais, que não implicam em empoderamento das unidades familiares. A capacidade reduzida de geração de renda deve-se também à fragilidade institucional dos agricultores, que dificulta a formação dos arranjos produtivos locais. Enfim, o PNPB, além de não interferir de forma significativa na dinâmica da produção da mamona, tem promovido resultados sociais inexpressivos.

Conclui-se que para que os arranjos produtivos agroenergéticos sejam sustentáveis, do tipo endógeno, os programas e açóes estratégicas governamentais náo podem ter uma orientação verticalista (de cima para baixo) e tampouco podem centrar-se somente na racionalização do espaço produtivo, mas devem valorizar o conhecimento e as experiências dos agricultores familiares, seus recursos naturais, dimensão tecnológica, organizacional e sócio-política.

\section{REFERÊNCIAS}

ABESS. Capacitação em Serviço Social e Política Social, Módulo 2, Brasília: CEADUNB, 1999.

ALDERFER, C.P. An empirical test and new theory of human needs. Organization Behavior of Human Performance, v.4, p. 142-175, 1969.

ALVES, A. M. S.; VASCONCELLOS, L. G. F. Desenvolvimento local e gestão municipal. Sociedade \& Natureza. v.17, n.32, p.15-26, 2005.

ARAÚJO, Rodrigo da Cruz de. Análise sobre a monocultura de soja e o Desenvolvimento Sustentável na Amazônia com base na teoria do Desenvolvimento Endógeno. Revista

Economia e Desenvolvimento, v.. 26, n. 1, p.105-118, 2014

AZEVEDO Simone Pereira de. Famílias monoparentais chefiadas por mulher: uma análise por estado civil. 2012, 111 f. Dissertação (Mestrado em Estudos Populacionais e Pesquisas Sociais) Escola Nacional de Ciências Estatísticas, Rio de Janeiro, ENCE, 2012.

BARBIER, E. "The economic linkages between rural poverty and land degradation: some evidence from Africa”. Agriculture, Ecosystems and Environment. v. 82, p. 355-370, 2000. 
BARDIN, L. Análise de Conteúdo. 5. ed. Lisboa: Edições 70, 2011.

ENGBERG, L. E. Rural Households and resource allocation for development: an ecosystem perspective. Rome: FAO, 1992.

FAVARETO, Arilson; MAGALHÁES Reginaldo; SCHRODER Mônica. Dilemas da inovação institucional e governança nos arranjos produtivos de biodiesel. In: XLVI

Congresso Brasileiro de Economia, Administraçáo e Sociologia Rural. Rio BrancoAcre: SOBER, 2008.

GOLDEMBERG, M. A arte de pesquisar: como fazer pesquisa qualitativa em ciências sociais. 5a ed., Rio de Janeiro: Record, 2001.

IBGE. Instituto Brasileiro de Geografia e Estatística. Censo Demográfico, 2010.

Disponível em: <http://www.ibge.gov.br>. Acesso em: 09/01/2014.

KEYNES, J.M. Economic possibilities for our grandchildren. In: Essays in persuation. London, MacMillan, 1972. p. 321-332.

LORETO, M. D. S.; CALVELLI, H. G.; LIMA, M. P. Cenário do Programa Nacional de Produção e Uso de Biodiesel: Uma Visão Sócia Institucional. In: IV Seminário Nacional de Sociologia \& Política. Curitiba: UFPR, 2012.

MARX, Karl. O capital. Volume I. 3a. edição, São Paulo: Editora Nova Cultural, 1982.

MARX, Karl; ENGELS, Friedrich. A ideologia alemã 6a . edição, São Paulo: Editora HUCITEC, 1987.

MASLOW, A. H. Motivation and a personality. New York: Harper, 1970.

METZEM, E.; WILLIAMS, F.L.; SHULL, J.; KEEF, D. R. Quality of life as affected by area of residence. I Project description. Columbia, University of Missouri, College of Agriculture, Agricultural Experiment Station, 1980. 112p. (Research Bulletin, 1036).

MONTALI, L. Arranjos familiares: o esforço coletivo para viver na Grande São Paulo. Cadernos de Pesquisa, São Paulo, Fundação Carlos. Chagas, n. 72, p. 58-61, 1990.

PENIDO, Marina de Oliveira. O Programa Nacional de Produçáo e Uso de Biodiesel: alternativa ou "mais do mesmo"? Do domínio do agribusiness à inserção da agricultura familiar na cadeia produtiva do biodiesel no Norte de Minas. 2011, $334 \mathrm{f}$. Dissertação (Mestrado em Geografia). Rio de Janeiro: Universidade Federal Fluminense, 2011.

PESSOA, V.; SOUZA, F.C. S.; REBOUÇAS, I. G. O Biodiesel como elemento de Desenvolvimento Sustentável no Semiárido Potiguar. Revista Holos. v.3, p.113-125, 2007. 
PFEIFER, Mariana; ADAMS, José Rodrigo Barth. Aspectos da concepçáo de produçáo/ reproduçáo social na teoria marxista. Disponível em: $<$ http://www.unicamp.br $>$. Acesso $04 / 10 / 2016$

PIETRAFESA, José Paulo. Agricultura familiar e reprodução social. Sociedade e Cultura, v. 3, n. 1 e 2, p. 185-216, 2000.

ROVARIS, A. Desenvolvimento da agricultura familiar do Norte e Nordeste. In:

Congresso Agribio, 2013. São Paulo, Agosto, 2013.

VASCONCELOS, M. Programa Nacional de Produçáo e uso de Biodiesel (PNPB).

Disponível em: <http://www.editoraferreira.com.br/publique/media/au_19_marcio.pdf>. Acesso em: 05/02/2016.

VILLACORTA, A. E; RODRIGUEZ, M. Metodologias e ferramentas para implementar estratégias de empoderamento. In: ROMANO, Jorge O; ANTUNES, Marta (Org).

Empoderamento e direitos no combate à pobreza. Rio de Janeiro: ActionAid Brasil, 2002.

YIN, Robert k. Estudo de Caso: Planejamento e métodos. Trad. Daniel Grassi. $3^{a}$ ed. Porto Alegre: Bookman, 2005.

WANDERLEY, M. de N. B. O mundo rural como um espaço de vida: reflexóes sobre a propriedade da terra, agricultura familiar e ruralidade. Porto Alegre: Editora da UFRGS, 2009.

WOORTMANN, K.; WOORTMANN, E. F. Monoparentalidade e Chefia Feminina: conceitos, contextos e circunstâncias. Série Antropologia, n. 357, 2004. 